\title{
Preliminary Study of Development of the Organization of Rare-Earth Exportation Countries (OREEC)
}

\author{
Takashi Kamei \\ Research Institute for Applied Sciences, Kyoto, Japan \\ E-mail: hae00675@nifty.com
}

\begin{abstract}
Cite as: Kamei, T., Preliminary Study of Development of the Organization of Rare-Earth Exportation Countries (OREEC), J. sustain. dev. energy water environ. syst., 1(1), pp 1-13, 2013,
\end{abstract} http://dx.doi.org/10.13044/j.sdewes.2013.01.0001

\begin{abstract}
The largest two sectors emitting $\mathrm{CO}_{2}$ in the world are electricity generation and land-transportation. Therefore, nuclear power plays an important role in generating electricity with low $\mathrm{CO}_{2}$ emission. An important aspect needs to be considered to ensure environmental sustainability is nuclear non-proliferation and less amount of radioactive waste generated. Thus the use of "thorium" as nuclear fuel has received increasing interest because thorium produces little amount of plutonium and very little amount of long-lived minor actinide. However, thorium cannot be used immediately due to its lack of fissile isotope indispensable to start fission reaction. At the same time, electric vehicle and hybrid-vehicle become more popular as low-carbon automobiles. Rare-earth elements are indispensable for manufacturing these low-carbon automobiles. However the problem with rare-earth production is its radioactive by-product of "thorium". Since the largest potential of consuming thorium by nuclear power still needs several decades for commercializing, there becomes a discrepancy in consumption and production of thorium causing unused stockpile of thorium. Several countries have announced to supply rare-earth but this cannot be safely and economically done unless thorium problem is solved. In this paper, an international framework called the "OREEC: Organization of Rare-Earth Exportation Countries” is proposed as a solution to this issue. The OREEC has mainly three functions: (1) ThAX, which is a financial collecting method, (2) Th FREE label, which is certification of adequate treatment of thorium and (3) The Bank, which stores separated thorium.
\end{abstract}

\section{KEYWORDS}

Rare-earth, Thorium, Storage, Financial support

\section{INTRODUCTION}

There are many different aspects need to be considered in developing sustainable society. One of the causes which obstruct sustainability is an artificial emission of carbon dioxide $\left(\mathrm{CO}_{2}\right)$. Therefore it is critical to reduce emission of $\mathrm{CO}_{2}$ from energy sector and transportation sector, which currently contributes to about $40 \%$ and $20 \%$ of the total world emissions, respectively [1]. For energy sector, emission reduction can be achieved partly by introducing renewable energy such as photovoltaic cells and wind-mills, whereas for transportation sector through the innovation of electric vehicle (EV) and hybrid vehicles (HV). From the industrial perspective, all of the above mentioned products use rare-earth elements as their main raw materials such as permanent magnet [2]. In the past few years, the environmental impact caused by radioactive thorium, which is a by-product of rare-earth refining process, has becoming a more significant environmental issue. This somehow indicates that the countermeasures taken for $\mathrm{CO}_{2}$ reduction by introducing renewable energies is actually resulting to additional environmental hazard associated with radioactive material [3]. The most well-known pollution event caused by thorium is that by 
Asian Rare-Earth in Malaysia in year 1994 [4]. But such pollution cases are not very much heard recently. This is because China has arisen as the largest (up to 97\%) producer of rare-earth in the world since year 2004 and the country has never disclosed the situation in the refining process to the public. Following the supply crisis triggered by the reduction of exportation licenses of rare-earth by China in August 2010, there are several activities initiated to develop rare-earth production process outside of China. However, it must be pointed out that the problem relating to thorium which was the major cause of enabling Chinese to monopolize rare-earth production has yet to be solved. For example, Australian Lynas is going to produce rare-earth using rare-earth ore mined from Australia by constructing their plant in Malaysia. This is because it is not allowed to build rare-earth refining factory in Australia due to environmental regulation. As a result, residents living around Lynas's factory in Malaysia voiced out their concern on treatment of thorium and to date, it is still uncertain if their rare-earth production plant will be operating as planned or not. The reason for concerning over thorium is that Malaysia and the production company itself recognized thorium as harmless and treated it just like any other wastes even though they follow IAEA's guideline. Therefore, it is difficult to attain social consensus both from the public community as well as the industry to invest certain amount of cost regarding thorium treatment for environmental protection.

Despite the issue discussed above, there is a possibility to use thorium as nuclear fuel. However, there is still uncertainty of the market demand for thorium and therefore it is not easy to store thorium as the potential energy source [5]. For example, thorium was stored by the U.S. government in 1950's because it was considered as the potential energy source in the near future. However, the national storage was terminated when enough reserves of uranium was confirmed. It can be said that thorium storage by nation was not done to satisfy any environmental related criteria, but merely for national energy security. Moreover, if thorium is used as nuclear fuel in near future, the amount of consumption will be very much limited and smaller compared to the estimated accumulation amount produced from rare-earth refining (as by-product). On the contrary to uranium which contains fissionable isotope having mass-number of 235, thorium does not have any fissionable isotope. This is a unique characteristics of thorium, which limits its utilization capacity [6]. So for using thorium as fertile material to produce fissionable material by absorbing neutron, external supply of fissionable material has to be prepared [7]. Naturally obtainable uranium-235 can be used for this purpose theoretically, but it needs high-enrichment up to $20 \%$, which consequently brings concern of nuclear proliferation. Though artificially generated plutonium is available to be used with thorium, stockpile of plutonium is not so large. The capacity of thorium fuel cycle supported by plutonium supply from uranium fuel cycle is expected to be around 400 GWe by year 2050. The consumption amount of thorium corresponding to this capacity will be around 76 thousand tonnes while accumulation of thorium from rare-earth refining may reach up to 222 thousand tonnes by 2050 [3]. Therefore, it is extremely necessary to construct an effective framework in order to protect the environment from exceeding amount of thorium. In the previous papers, a new concept called “The Bank (Thorium Energy Bank)” was proposed for satisfying this requirement [8, 9].

The reason for a problem related to wastes such as thorium and $\mathrm{CO}_{2}$ difficult to be solved is due to the fact that the receivers of benefit from the process which generates these wastes and the receivers of risk associated with these wastes are different. Therefore in this paper, environmental protection from thorium produced as by-product from rare-earth production is discussed. A framework called the OREEC (Organization of Rare-Earth Exportation Countries) will be proposed as a mechanism to unify the receivers of benefit and risk relating to rare-earth usage. The approach on how to collect the cost of 
environmental protection from thorium is described. Preliminary evaluation of cost required for treating thorium will be reported.

\section{THE OREEC (ORGANIZATION OF RARE-EARTH EXPORTATION COUNTRIES)}

\section{Outline of the OREEC}

The OREEC is an international organization established for protecting the environment from thorium occurred as by-product of rare-earth refining. The problem with thorium is that it has structural characteristics that exist on international trades of rare-earth. In other words, the environmental problem of thorium occurs only at the rare-earth production country. But the countries importing this rare-earth are not affected by thorium and they do not pay attention to the occurrence of thorium as by-product. In order to overcome this kind of cross-border issue, an international framework should be considered.

Thorium is an external economy or externality because it does not have value in presently existing economy $[10,11]$. Therefore, treatment against thorium pollution does not spontaneously happen as far as based on ordinary economic activity. This is same for $\mathrm{CO}_{2}$ case. The OREEC provides a mechanism to collect financial support by internalizing the above-mentioned externality. This is called "ThAX (Thorium t $\underline{\mathrm{AX}}$ )". ThAX is collected by adding some value to selling price of rare-earth when it is exported. ThAX is used so as to contribute to environmental protection from thorium. ThAX is not an additional profit of rare-earth sales. The amount of ThAX is purely determined by technological evaluation of thorium separation process and thorium storage. Then it is added to the rare-earth price which can be determined by market principle.

The OREEC guarantees the rare-earth refining factory that they take care of the environmental protection from thorium by preparing thorium separation process. This is called "Th FREE Lable (Th is thorium)". The OREEC owns a function to store the separated thorium. This is called "The Bank (Thorium Energy Bank)". The detail of The Bank has been reported in PBNC2012 [9].

\section{Joining the OREEC}

There are many countries having rare-earth resources. However, rare-earth production is dominated $97 \%$ by China. This monopoly was achieved by China's dumping in 1990's. The U.S. which produced rare-earth before Chinese era and Australia who had a plan to produce rare-earth had to stop their production or terminate plan because they could not have commercial competitiveness as long as they took care of thorium adequately. The low price of rare-earth production could be supported without taking care of thorium. It was not able to keep market competitive power as far as the countries took care of thorium. In addition, the principles of several countries which only used rare-earth and did not pay attention to the thorium problem e.g. Japan had contributed to continuous rare-earth production in China without taking care of the thorium related problem. Rare-earth price has increased after Chinese monopoly on the rare-earth production ended and this leads to the kick-off of rare-earth production in countries other than China after 2010. However, once China decreases rare-earth price, same game is expected to happen as we saw in 1990's again. As is shown above, rare-earth production countries are often different from its consumption countries and the pollution problem associated with thorium generation is hidden under this international trading.

The OREEC (1) overcomes the present situation in which the issue of thorium is not involved in the economic activity including international trading, (2) eliminates or reduces environmental impacts caused by thorium by keeping fairness of receiving benefit and risk 
between rare-earth production countries and its consumption countries, (3) and constructs framework enabling health market mechanism to decide the rare-earth price. Thus the OREEC requires its attendee for strict examination before joining the organization and inspection after being a member state of the OREEC. The way how to internalize externality of thorium has been described before [3]. Required conditions for joining the OREEC is summarized in Table 1.

Table 1. Required conditions for joining the OREEC

\begin{tabular}{cccccc}
\hline & Reserve & Refining & Exportation & Candidate & Attend \\
\hline Case 1 & Yes & $\underline{\text { Yes }}$ & $\underline{\text { Yes }}$ & USA? & OK \\
\hline Case 2 & Yes & Yes & No & China? & NO \\
\hline Case 3 & No & $\underline{\text { Yes }}$ & $\underline{\text { Yes }}$ & Malaysia? & OK \\
\hline Case 4 & No & Yes & No & Japan? & NO \\
\hline Case 5 & No & No & Yes & Somewhere & NO \\
\hline Case 6 & Yes & No & No & Australia? & NO \\
\hline
\end{tabular}

Decision of joining the OREEC is done by taking into account both that (1) the country has an operated rare-earth refining factory, (2) part of the products from this factory is exported. The existence of rare-earth reserve in the country is not considered. If a country exports rare-earth products by importing refined rare-earth ore which does not contain thorium, this does not satisfy requirement of the OREEC (Case 5). This is because there is no risk of occurring thorium pollution in this country. Even though a country refines rare-earth and does not export it, this is also not a member of the OREEC (Case 2). There is a possibility that thorium pollution may occur within this country but the country should treat this by its own responsibility.

\section{Guarantee}

Countries which wish to join the OREEC are requested to provide guarantee that they will make application of equipment to protect environment from thorium. This guarantee will be returned back when the country terminates the member states of the OREEC by eliminating the amount used for recovering pollution if there is throughout the country being a member of the OREEC. Termination of member state of the OREEC will take place when they stop rare-earth production. Decommission of the factory and cleaning of tail must be done by the private company or the country owning the factory.

Member states of the OREEC have duty to be inspected to confirm their suitable application of treatment of thorium (separation and storage) to the rare-earth factories in the state. The inspection contains non-interval examination and full-time detection of radioactivity at the factory and its circumference. The data of production amount of rare-earth and its characteristics must be provided to the OREEC. These data are used to estimate the amount of thorium separated and to compare with the actual separation amount.

If the country owns active rare-earth refining factory since before joining the OREEC and the factory does not have facilities to separate thorium, the country has duty to apply such equipment for this factory. ThAX which is accumulated before this country joining the OREEC can be used for this country's preparation of thorium treatment. If there is no enough amount of ThAX, above mentioned guarantee is used for this purpose. This usage of guarantee will be compensated once corresponding amount of ThAX is accumulated. If there is thorium pollution, cleaning of this pollution is required. ThAX can also be used for this cleaning. 
If thorium pollution occurs after joining the OREEC, ThAX is used for its recovery except for the case that the pollution originates from a rare-earth factory which is not declared to the OREEC. This exception is because the factory is not under the control of the OREEC. Guarantee will be used for this cleaning. If the amount of the guarantee is not enough, the factory or the country must pay for it.

\section{Annual congress}

Annual congress of the OREEC is organized by all member states and it is held at least once in a year. Primary subjects are (1) determination of value of the ThAX, (2) confirmation of balance of the ThAX, (3) review of thorium treatment, and (4) acknowledging new member states. Non-periodic congress will be held upon an occurrence of thorium pollution caused by natural disaster such as earthquake. The approach of how to take care of the pollution will be discussed. The OREEC gathers scientific information and technology not only to protect the environment from thorium but also to recover the polluted environment from thorium.

\section{Propriety right and right of use of thorium}

Propriety right of thorium separated in the factory of the member states of the OREEC is owned by the OREEC. This essential policy is determined to avoid possibility that the separated thorium is thrown into the environment as far as the propriety right of thorium is owned by the country or private company. In other words, the responsibility of environmental protection from thorium is shared internationally by moving the propriety right of thorium to the OREEC.

However, by considering the future value of thorium as energy source, the right of use of thorium can be held by each country or private company. This thorium is called "Deposit". The right of use of thorium basically remains in the owner of rare-earth ore before refining. For example, if the rare-earth refining factory itself imports, this factory owns the right of use of the separated thorium. If there is a regulatory that the separated thorium must be owned by the country where the factory exists, the country keeps the right of use of the separated thorium. There is no need to pay for keeping deposit even though they are allowed to use the OREEC's storage function. If these factories or countries want to renounce even the right of use of the separated thorium, they can move the right of use to the OREEC. This is called "Transfer". Transfer is done without any payment to these factories or countries from the OREEC. It is allowed to keep part of the separated thorium as deposit and to transfer the rest.

\section{Trading market of thorium "TREX"}

Though there is a possibility that the thorium may have value in the future, but there is no value as for now [5]. Therefore, at the moment what needs to be considered is just the cost to separate and store thorium. It is not easy to put responsibility of managing thorium to each country and private company. On the contrary, the framework of the OREEC provides both certain environmental protection from thorium by putting the responsibility to the OREEC and keeping the right of usage of thorium in each country and private company by considering future value of thorium as energy source.

It is not necessarily possible that a county has motivation to use their own deposit if the country has other energy sources. In this case, this country's deposit of thorium does not appeal value as energy source. On the other hand, there will be a country that want to use thorium as energy and does not have deposit in the OREEC. This country will not spend another cost to develop new mines of thorium as far as this country's economy depends on market principle because separated thorium has already stored in the warehouse of the 
OREEC. And the excess amount of thorium as deposit and transfer in the warehouse of the OREEC is enough larger than available consumption amount of thorium till 2050. However, this country cannot purchase this separated thorium from ordinary market because this deposit and transfer belongs to the OREEC. In order to solve this inconvenience, the OREEC provides a market to trade the right of use of thorium. This is called "TREX: ThoRium EXchange market”.

The reason why this kind of market must be prepared within the framework of the OREEC is that unfair increase of thorium (the right of its use under the OREEC) price should be avoided which often happens in the face-to-face trading. A country wanting to use thorium can declare to use transfer than purchasing deposit. Use of transfer will be done without payment. It must be pointed out that this declaration of transfer is not to use as a deposit but to utilize the thorium at the moment of declaration. Therefore, it is allowed as far as the declaring country has their nuclear reactor and consumption plan. On the contrary to this, trading of deposit in the TREX can be done for keeping the right of use considering future consumption of thorium. If some country wants to have deposit again once they transferred their deposit, it must be done in the TREX and has to pay against the OREEC.

\section{ThAX}

The cost used for separating and storing thorium by the member states of the OREEC is collected by adding it to selling price of rare-earth exportation from the rare-earth refining factory as shown in Fig. 1. This is called "ThAX". Value of the ThAX can be determined based on each element of rare-earth and per weight. Value of the ThAX is common for all importation countries and exportation countries. If the value of the ThAX is too small, it is unable to take care of thorium adequately. It is expected to be somewhat large value when rare-earth separation facilities are applied and warehouses are constructed. Once these facilities are prepared, only operation cost is required and the value will be reduced during a discussion of annual congress of the OREEC. On the other hand, too much large value of the ThAX does not enable it to be purchased even suitable treatment of thorium is done. Therefore, it can be said that the value of ThAX will be rationally decided based on both market mechanism and technical availability. Needless to say, the price of rare-earth itself is determined by each country's and company's ability.

Rare-earth product goes through custom clearance where its shipping factory is located for a case of exportation. The custom clearance provides the information (terms and condition including goods, amount, price and day of payment) to agent of the OREEC in the country. Purchase fee of rare-earth importation will be paid to the rare-earth factory based on the terms and condition. Based on the same information, agent of the OREEC requests this factory to pay corresponding amount of ThAX including in the selling price of the rare-earth exportation.

The collected ThAX of each transaction of rare-earth trading is not used by the country where the rare-earth is exported but shared by all member states of the OREEC. ThAX is not added to the selling price of rare-earth to inland transaction of the factory because this is not exportation. 


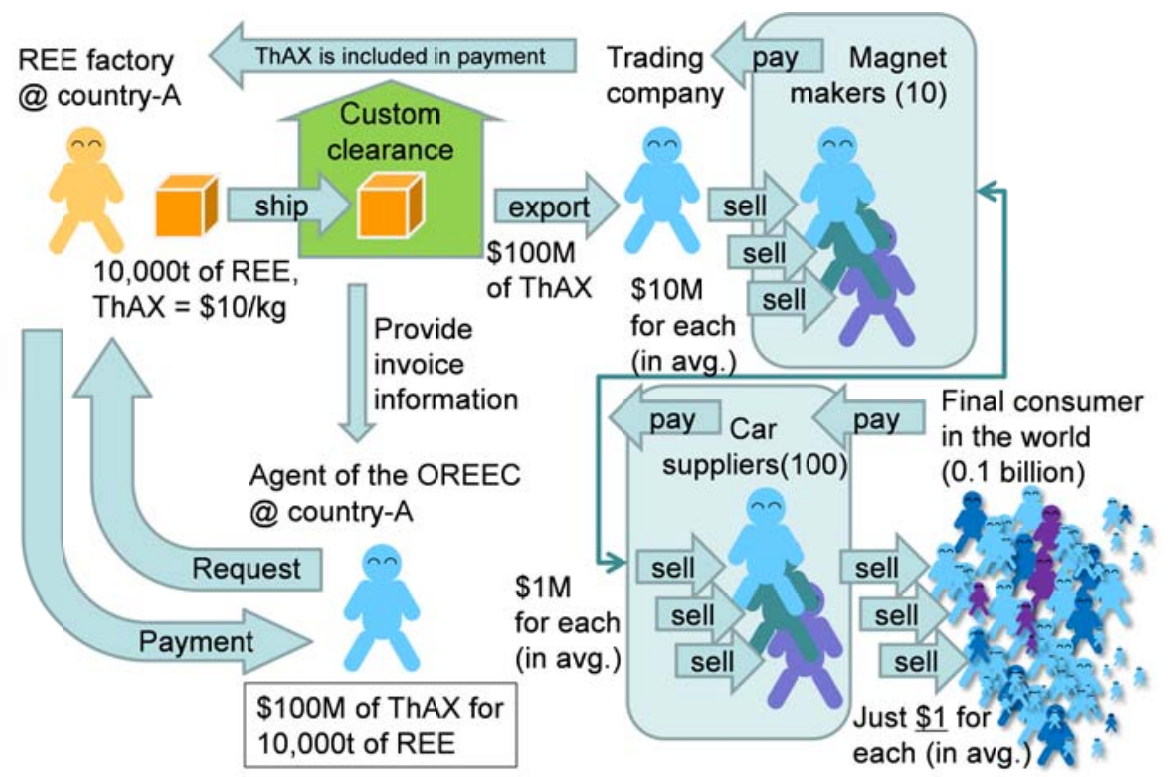

Figure 1. Collection of the ThAX

Trading company of rare-earth importation will sell their commodity to magnet maker by including value of the ThAX. Here, the original amount of the ThAX will be divided into the number of the makers which purchase rare-earth raw materials. The magnet maker will sell their products to electric-motor maker by including the ThAX as well. The electric-motor makers will do the same to automobile companies. The automobile makers will sell their EV and HV to final consumers with the ThAX divided into small pieces. Thus payer of the ThAX actually goes to the final consumer. Finally, a framework can be constructed by conducting the mechanism of the OREEC enabling foreign country's final consumers who receive benefit of utilizing rare-earth to pay cost to take care of thorium which occurs at country which has risk of rare-earth production.

\section{Storage of thorium (The Bank)}

The separated thorium will be stored in "The Bank" which locatedl under the OREEC. Detail of The Bank is described in the references [8, 9]. Location of warehouse is determined by regulation of The Bank and it is not necessarily the same country having rare-earth refining factory.

The Bank describes its operation plan every year including construction of new warehouse and reports requiring cost at the annual congress of the OREEC. The OREEC will certificate as far as the plan is reasonable. It should be noticed here that all of the separated thorium has to be stored in The Bank even though only part of the rare-earth production is exported.

\section{Th FREE Label}

The OREEC will provide certification to the rare-earth refining factory once it is confirmed that the factory equips suitable treatment of thorium. This certification is called "Th FREE Label". (See Fig. 2) Certificated factory is allowed to use this label on their walls, pamphlet, website etc. User purchased rare-earth from certificated factory is also allowed to use Th FREE Label. The use of Th FREE Label is allowed for users both inland and in foreign countries. Those users wanting to use Th FREE Label need to contact the OREEC to provide the label. 


\section{- Will be put anywhere which use REE}

- EV, HV, PV, Wind-mill, mobile phone, Fighter, Radar...
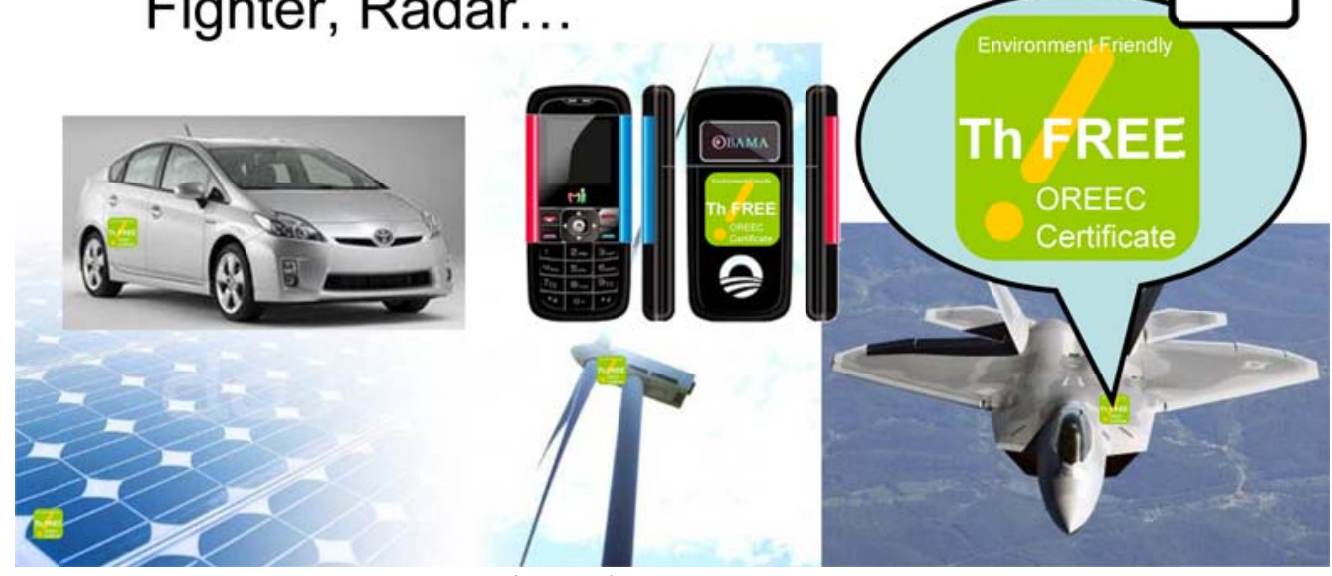

Figure 2. Th FREE Label

\section{RESULTS}

Results of the preliminary simulation of annual trend of ThAX and its accumulation will be presented here. In this study, the value of ThAX is determined to be common for all rare-earth elements. Calculation is done from year 2012 to 2050. Rare-earth production amount in the world is obtained by USGS's estimation [12]. AIST's data does not provide nation dependent information. Therefore, it is assumed in this work that the U.S. and Australia produce 10 thousand tonne from 2012 and they expand their production amount up to 50 thousand tonne till 2050. India produces 5 thousand tonne steadily. The rest will be provided by China. That is to say, production share by China will be around $79 \%$ at 2050 . This estimation is shown in Fig. 3. Though it is reported that there are several countries showing interest to provide rare-earth such as Brazil, Turkey and Vietnam, these countries are not included in this study.

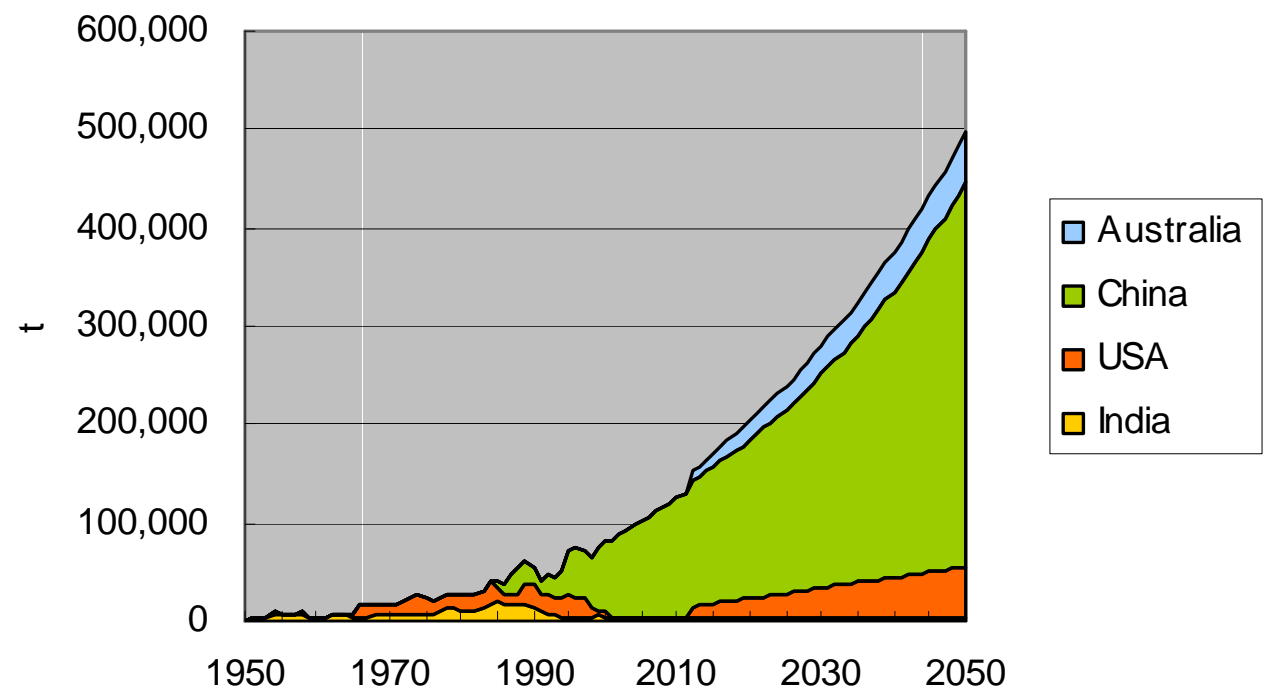

Figure 3. Annual production of rare-earth 
Production amount of thorium as by-product is determined based on the above production amount of rare-earth and the content of thorium in their major rare-earth ore. In this study, it is simply determined that the content of thorium is $4 \%$ for the U.S., $12 \%$ for Australia, 19\% for India and 1\% for China, respectively. The reason why Australia and India have larger thorium content is their major ore is Monazite. Accumulating amount of thorium is shown in Fig. 4.

As can be clearly seen from Figs. 3 and 4, India's accumulation of thorium is large in spite of its small production amount of rare-earth. Though India has their energy policy to put thorium utilization in nuclear power, it cannot be said that India will expand thorium storage by taking account of available thorium consumption and relating cost. This means that it cannot be expected that India will expand their production amount of rare-earth. Occurrence of thorium from Australia is also large. This is because rare-earth production is increased in spite of their high containing ratio of thorium. Since Australia has no plan to utilize thorium as their nuclear fuel, it is implied that thorium treatment will be a big issue. China has already decided to use thorium as their nuclear fuel. The U.S. may use thorium but it is still uncertain at the moment.

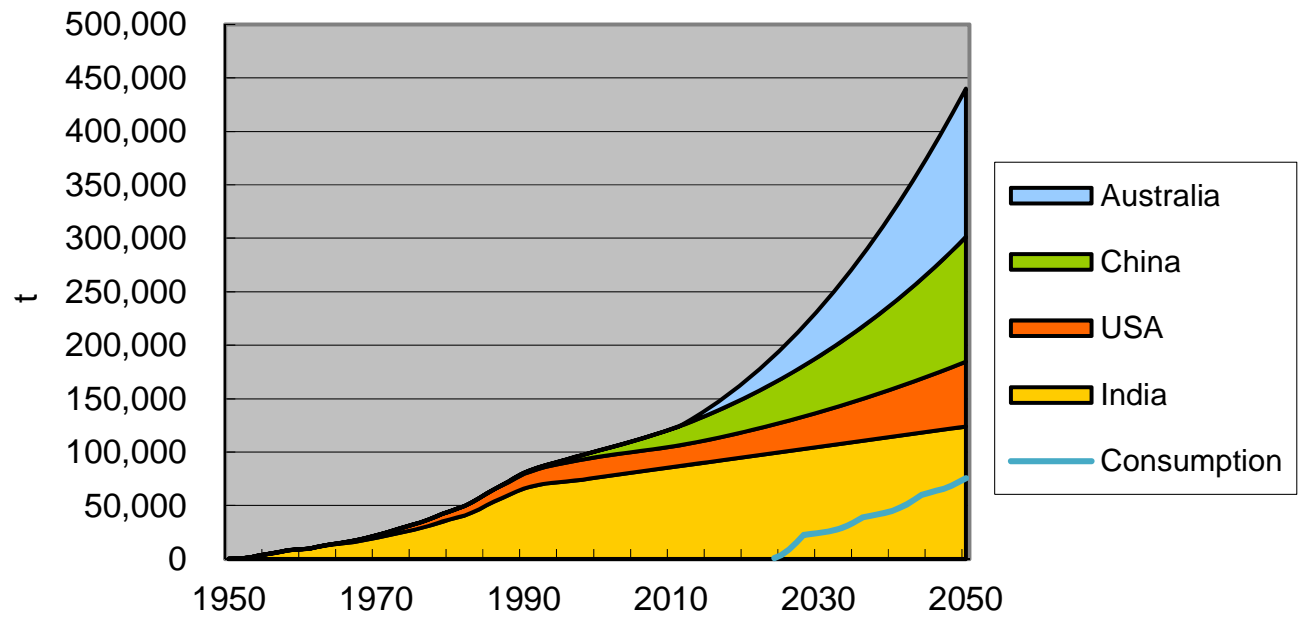

Figure 4. Annual thorium accumulation

Joining of these four countries to the OREEC is determined as follows.

It is assumed that India will export all amount of rare-earth. This is because thorium is the main target and rare-earth is by-product in India and there is no significant industry to use rare-earth for metallurgy to produce magnet. This satisfies requirements of the OREEC for joining. However, other requirements to shift propriety right of thorium will not be accepted by India even though the right of use is allowed. As mentioned before India's most important energy policy is to utilize thorium as nuclear fuel, thorium is stored adequately not for losing this valuable material. As a result, the environment is not affected by thorium itself.

One advantage to join the OREEC is to enable using ThAX to rare-earth price. This is also not attractive to India because there is a country such as Japan who wants to purchase rare-earth with large price which is valueless to India. Otherwise, if there is no country that purchases India's rare-earth, it is not a problem for India. Thus it is assumed that India will not join the OREEC.

China has already announced that they will use thorium. It can be projected that they will have interest in ThAX which can be used for China's environmental recovery. However, it also can be expected that they will stop exportation because rare-earth 
consumption in China is increasing drastically. That is to say, China will be a country who produces rare-earth but does not export. This does not satisfy the OREEC's requirement.

In the U.S., Molycorp is going to re-start production of rare-earth at Mt. Pass from year 2012. Molycorp produced rare-earth until 1990's. The U.S. itself stored thorium as national resource for nuclear energy until the end of 1950's but the policy was terminated because abundant uranium resource was confirmed. It can be said that the U.S. may recognize merits of the OREEC which has a function to collect ThAX for spending thorium treatment because the U.S. notices both the importance of protecting environment from thorium and its cost. In addition, the U.S. also understands it takes time to commercialize thorium utilization as nuclear fuel. Thus, another function of the OREEC to keep right of use of thorium than its propriety right may be considered as a rational way to remain possibility of thorium utilization. The U.S. also will be a great consumer of rare-earth and loose available capacity for exportation but Molycorp announced in 2011 that they will provide at least half of their product to Japan. Therefore the U.S. satisfies the requirements to join the OREEC in this study.

Australia does not have significant capacity of rare-earth utilizing industry and therefore exports all the products. It is of course necessary to take care of thorium in Australia. In this manner, it can be thought that Australia will join the OREEC. However, rare-earth refining factory cannot be built in Australia due to its environmental regulation and Australian Lynas has built their factory in Malaysia. Separated thorium is going to be stored in Malaysia. Taking into account of this situation, it is assumed here that Malaysia will join the OREEC which imports Australia originated rare-earth ore.

Simulated results of annual trend of unit value of ThAX and its balance between accumulation and consumption are shown in Fig. 5 and Fig. 6, respectively. Assumptions considered in this simulation are as follows. Thorium utilization as nuclear fuel will not be commercialized before year 2050. The OREEC starts its operation from 2012. One warehouse of the OREEC for storing thorium has 50 thousand tonne of thorium per one unit and its construction cost is 50 million USD. Its operational cost is 5 million USD per year. Separation facility of thorium attached to each rare-earth refining factory requires 10 million USD per unit. Warehouses and separation facilities are assumed to be completed and available by year 2012 .

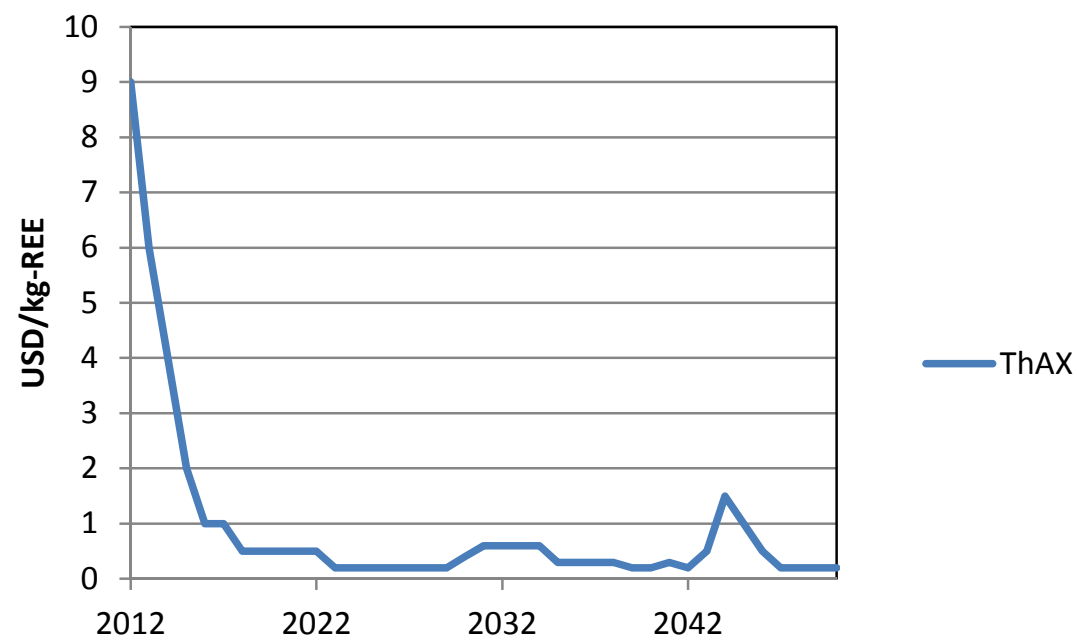

Figure 5. Annual trend of unit value of ThAX 


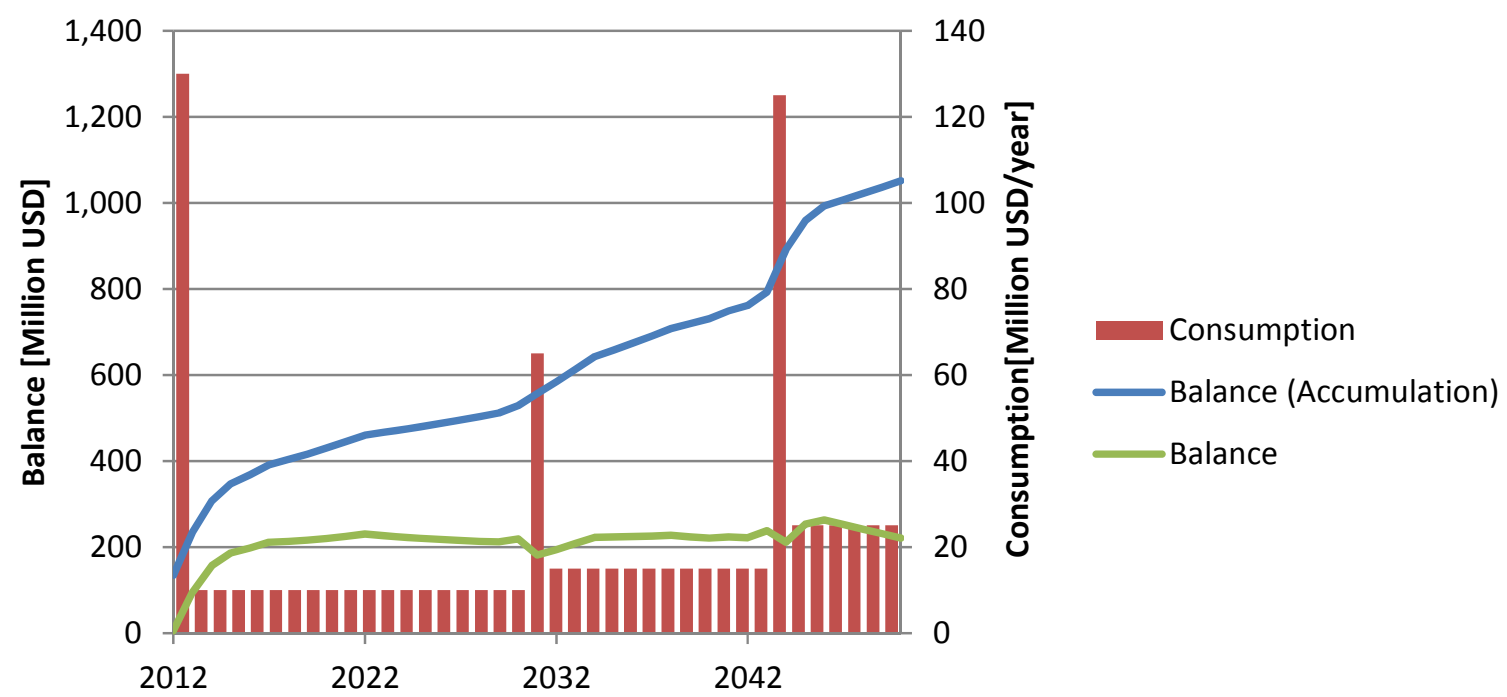

Figure 6. Annual trend of accumulation and consumption of ThAX

There is no accumulation of ThAX in the beginning of 2012. At the same time, investment for constructing warehouses and equipping separation facilities are necessary in this year. Therefore, unit value of ThAX for $1 \mathrm{~kg}$ of rare-earth product is determined to be 9 USD. Then, ThAX will be adjusted so as to accumulate and sustain for its balance after consumption being around 200 million USD. This sustained value is prepared for an unexpected large leakage accident of thorium caused by natural disaster. Though initial value of ThAX can be set much smaller by using guarantee which is collected from member states when they join the OREEC, it was not considered in this study.

The reason why ThAX increases around year 2030 is that the first thorium warehouse prepared for Malaysia exceeds its capacity and the second warehouse is constructed. In spite of large requirement of construction cost, its value being 0.6 USD is much smaller than the original value being 9 USD. Once accumulation of ThAX reaches 200 million USD, the value of ThAX is reduced. In the same way, ThAX increases again around year 2044 because the U.S.'s first warehouse and Malaysia's second warehouse exceed their capacity. New warehouses are built in these countries.

It can be summarized from these results as follows;

1) Initial unit value of ThAX will be relatively large in the beginning of the OREEC.

2) Unit value of ThAX will be reduced once investments are finished.

3) Unit value of ThAX will be increased for additional application of investments.

4) Unit value of ThAX will be smaller than the present rare-earth price (ex. 100 USD/kg-Dy).

5) Capacity of warehouse will be decreased once thorium is utilized.

Though there will be discussions how to share the cost of past years' pollution, the use of ThAX will be a rational one as far as it should be done within this generation.

As shown in Fig. 3, rare-earth production amount is the same between the U.S. and Australia. If the U.S. exports all amount of rare-earth, total value of ThAX between the U.S. and Australia will be the same. On the other hand, the amount of occurring thorium is different because of their concentration of thorium. As a result, number of warehouse for Malaysia which imports Australian rare-earth ore becomes larger than that of the U.S. The cost for constructing warehouses for Malaysia is provided from the total accumulation of 
ThAX in the OREEC, not from the ThAX collected via Malaysia's custom clearance. That is to say, each ThAX collected at each country's custom clearance is not used for the country itself. This is a principal policy of the OREEC.

Once U.S.'s Molycorp refines U.S. originated monazite at refining factory located inside of the U.S. and exports half amount of their production to Japan, ThAX will be added to this exported rare-earth. Japan can import clean and stably supplied rare-earth after adequate treatment of thorium removable by paying ThAX. Clean and sustainable products such as TOYOTA's "PRIUS" will be manufactured by using this clean rare-earth and sold to customers living in all over the world with a price including thinly spread ThAX. The mechanism of the OREEC enables final customers to pay their own responsible cost to take care of thorium in a rational way.

\section{CONCLUSION}

A probability of rare-earth production with keeping competitive market power and environmental protection from thorium which occurs as by-product of rare-earth refining process is indicated as the OREEC. Remaining subjects for future studies are as follows;

1) Detailed discussion of cost of thorium separating facility, thorium storing warehouse

2) Expansion of rare-earth production countries such as Brazil

3) Tendency of ThAX based on each rare-earth element (i.e., Nd, Ce, Dy and so on)

4) Termination from the OREEC (ex, equipped facility, thorium Deposit)

5) Effect of ThAX to the price for final commodity (e.g. electric vehicle)

6) Termination of the OREEC (e.g. accumulated ThAX)

7) Attend of China and India

8) Tendency of stockpile of thorium under its utilization (e.g. commercialization before 2050)

9) Activity of TREX

10) Effect of reduction of exportation (e.g. from the US or no exportation)

11) Operational cost for the OREEC itself

12) Storing exceeding amount of rare-earth

\section{ACKNOWLEDGMENT}

This work was supported by KAKENHI (2171015 2) for Grant-in-Aid for Young Scientists (B).

\section{REFERENCES}

1. IEA, World Energy Outlook, (2007).

2. Kamei, T., "A technical approach to the low carbon society based on the new nuclear power utilizing thorium”, Proc. of SDEWES2009, Dubrovnik, CD-ROM (2009).

3. Kamei, T., "Study of nuclear environment \& material strategy", International Electronic Journal of nuclear safety and simulation, Vol.2, No.4, 2011.

4. Bradsher, K., "Mitsubishi Quietly Cleans Up Its Former Refinery”, the New York Times, March 8, 2011.

5. Hesketh, K. and Worrall, A., “The thorium fuel cycle”, National Nuclear Laboratory, August, 2010.

6. Kamei, T., "Symbiotic energy demand and supply system based on collaboration between rare-earth and thorium utilization", International Electronic Journal of nuclear safety and simulation, Vol.2, No.2, 2011. 
7. Kokubo, Y. and Kamei, T., "Conceptual design of thorium-fuelled Mitrailleuse accelerator- driven subcritical reactor using D-Be neutron source”, Proc. of PHYSOR2012, Knoxville, USA, 2012, April 15-20.

8. Kamei, T. and Hakami, S., "Evaluation of Implementation of Thorium Fuel Cycle with LWR and MSR”, Progress in Nuclear Energy, Vol.53, No.7, 2011. (http://dx.doi.org/10.1016/j. pnucene.2011.05.032)

9. Kamei, T., "The indispensable role of thorium for creating a sustainable society”, Proc. of PBNC2012, Busan, Korea, 2012, March 18-23.

10.Pigou, A.C., 1932, The Economics of Welfare, $4^{\text {th }}$ ed., London.

11.ExternE 1999: Externality of Energy, European Commission, Directorate General XII, Science, Research \& Development, Luxembourg, 1999.

12. Thorium Minerals Yearbook, USGS, 2009. 